\title{
TGF- $\beta 1$ induces apoptosis of bone marrow-derived mesenchymal stem cells via regulation of mitochondrial reactive oxygen species production
}

\author{
FENXI ZHANG ${ }^{1,2}$, TONGMING REN ${ }^{1}$ and JUNFANG WU ${ }^{3}$ \\ ${ }^{1}$ Department of Anatomy, Sanquan College; ${ }^{2}$ Stem Cell Center; ${ }^{3}$ Morphology Laboratory, \\ Xinxiang Medical University, Xinxiang, Henan 453003, P.R. China
}

Received August 25, 2014; Accepted June 11, 2015

DOI: $10.3892 / \mathrm{etm} .2015 .2590$

\begin{abstract}
Bone marrow-derived mesenchymal stem cells (BMSCs) are the most promising seed cells in regenerative medicine. Our previous study demonstrated that transforming growth factor (TGF)- $\beta 1$ induced BMSC senescence in vitro. Whether TGF- $\beta 1$ affects the apoptosis of BMSCs has not been examined; therefore the aim of the present study was to investigate this effect. BMSCs were isolated from mouse bone marrow, and the third-passage cells were exposed to 0,10 and $20 \mathrm{ng} / \mathrm{ml}$ TGF- $\beta 1$ for $24 \mathrm{~h}$. Cell proliferation was measured by MTT assay; apoptosis was assessed using DAPI staining; and the apoptotic signals Annexin V, B-cell lymphoma (Bcl)-2 and $\mathrm{Bcl}-2$-associated $\mathrm{X}$ protein (Bax) were measured using western blotting. Mitochondrial reactive oxygen species (ROS) were measured by flow cytometry following staining with MitoSOX ${ }^{\mathrm{TM}}$ Red mitochondrial superoxide indicator. The MTT assay showed that 10 and $20 \mathrm{ng} / \mathrm{ml}$ TGF- $\beta 1$ inhibited BMSC proliferation. DAPI staining demonstrated that 10 and $20 \mathrm{ng} / \mathrm{ml}$ TGF- $\beta 1$ promoted BMSC apoptosis, which was further confirmed by a western blotting assay showing a significant increase in the pro-apoptotic signals Annexin V and Bax but a decrease in the anti-apoptotic signal Bcl-2. It was also found that TGF- $\beta 1$ markedly increased the mitochondrial ROS levels in BMSCs. It is well known that mitochondrial ROS are strong stimulators of cell apoptosis. These findings indicate that TGF- $\beta 1$ can induce BMSC apoptosis, and the mechanism may involve mitochondrial ROS generation.
\end{abstract}

Correspondence to: Dr Fenxi Zhang, Stem Cell Center, Xinxiang Medical University, 601 Jinshui Road, Xinxiang, Henan 453003, P.R. China

E-mail: fxzhang0824@gmail.com

Key words: transforming growth factor- $\beta 1$, bone marrow-derived mesenchymal stem cells, apoptosis, mitochondrial reactive oxygen species

\section{Introduction}

Bone marrow-derived mesenchymal stem cells (BMSCs) are multipotent stromal cells with the potential to differentiate into a variety of cell types, including adipocytes, osteocytes, cardiomyocytes and neurons (1). Recently, BMSCs have been used to treat acute and chronic myocardial infarction. Transplantation of BMSCs into the left ventricle has been demonstrated to decrease the infarcted area, inhibit left ventricular remodeling and improve cardiac function in patients with myocardial infarction or animal models with heart ischemia (2-5). Generally, BMSCs need to be induced in vitro by special reagents for cardiomyogenic differentiation. Transforming growth factor- $\beta 1$ (TGF- $\beta 1$ ) is one of the most commonly used reagents for inducing the cardiomyogenic differentiation of BMSCs (6-8). Previous studies have indicated that TGF- $\beta 1$ treatment in vitro promotes the transformation of BMSCs into cardiomyocyte-like cells that express cardiomyocyte-specific markers (6-8).

TGF- $\beta 1$ is a growth factor with multiple functions. It not only affects cell differentiation but also plays diverse roles in regulating cell proliferation, migration, apoptosis and autophagy (9-11). Previous studies have indicated that TGF- $\beta 1$ inhibits the proliferation of epithelial cells, cardiac fibroblasts, hematopoietic cells and cancer cells but promotes the proliferation of vascular smooth muscle cells, skin fibroblasts, endothelial cells and other specialized cells (12-14). TGF- $\beta 1$ has also been demonstrated to induce the apoptosis of a wide range of cells (15-17). Mitochondrial reactive oxygen species (ROS) are a family of reactive molecules that can trigger cell apoptosis by damaging mitochondrial DNA (18). It is known that TGF- $\beta 1$ can induce mitochondrial ROS production in numerous cell lineages (19). Our previous study showed that TGF- $\beta 1$ induced BMSC senescence by promoting mitochondrial ROS generation (20); however, whether TGF- $\beta 1$ induces the apoptosis of BMSCs through the regulation of mitochondrial ROS production has not been elucidated, and this topic is a focus of the present study.

\section{Materials and methods}

Animals. A total of 6 male C57BL/6 mice (8 weeks old) were obtained from the Experimental Animal Center of Xinxiang 
Medical University (Xinxiang, China). The study protocol and animal use were approved by the Ethics Committee of Xinxiang Medical University. Animal treatment was strictly performed according to the Guidelines of the Ministry of Science and Technology of the People's Republic of China (approval no. 2006-398).

Isolation and culture of BMSCs. BMSCs were isolated and cultured according to a recently published protocol (21). The third-passage BMSCs were exposed to 0, 10 and $20 \mathrm{ng} / \mathrm{ml}$ recombinant mouse TGF- $\beta 1$ (Cell Signaling Technology, Inc., Danvers, MA, USA) for $24 \mathrm{~h}$, and cell proliferation, apoptosis and mitochondrial ROS were subsequently measured.

MTT assay. BMSC viability was measured with an MTT assay kit (American Type Culture Collection, Manassas, VA, USA) following exposure to different concentrations of TGF- $\beta 1$. The third-passage BMSCs ( $3 \times 10^{3}$ cells/well) were placed in 96-well plates and cultured with Dulbecco's modified Eagle's medium (DMEM) without serum overnight. The next day, the medium was replaced with complete DMEM (with $15 \%$ serum) supplemented with 0,10 and $20 \mathrm{ng} / \mathrm{ml}$ TGF- $\beta 1$, and the cells were cultured for an additional $24 \mathrm{~h}$. A total of $10 \mu \mathrm{l}$ MTT reagent was then added to each well and the plates were incubated at $37^{\circ} \mathrm{C}$ for $2 \mathrm{~h}$. Following incubation, MTT detergent reagent $(100 \mathrm{ml})$ was added to each well and the plates were incubated at room temperature for $2 \mathrm{~h}$ in the dark. Finally, absorbance at $570 \mathrm{~nm}$ was read using a plate reader (Bio-Rad Laboratories, Inc., Hercules, CA, USA).

Apoptosis assay. Cell apoptosis was measured using DAPI (Beyotime Institute of Biotechnology, Shanghai, China) staining. BMSCs $\left(1 \times 10^{5}\right.$ cells/well) were seeded in $24-w e l l$ plates with round coverslips and exposed to 0,10 and $20 \mathrm{ng} / \mathrm{ml}$ TGF- $\beta 1$ for $24 \mathrm{~h}$. Following washing with phosphate-buffered saline (PBS), the cells were fixed with buffered paraformaldehyde and incubated with $0.1 \%$ Triton $^{\mathrm{TM}} \mathrm{X}-100$ (Bao Biological Engineering Co., Ltd., Dalian, China) for $10 \mathrm{~min}$ at room temperature. The cells were treated with DNase-Free RNase $(50 \mathrm{mg} / \mathrm{ml})$ for $3 \mathrm{~h}$ at $37^{\circ} \mathrm{C}$ and then stained with $5 \mu \mathrm{M}$ DAPI for $5 \mathrm{~min}$ at room temperature. Cell apoptosis was assessed under a fluorescence microscope (Olympus Corp., Tokyo, Japan). The cells with a condensed nucleus or a nucleus with irregular edges were considered to be apoptotic.

Western blotting. Following treatment with different concentrations of TGF- $\beta 1$ for $24 \mathrm{~h}$, proteins were extracted from the BMSCs using a protein extraction kit containing $20 \mathrm{ml} 5 \mathrm{X}$ lysis buffer, $0.5 \mathrm{ml}$ protease inhibitor, $0.5 \mathrm{ml}$ phosphatase inhibitor and $0.5 \mathrm{ml}$ phenylmethylsulfonyl fluoride (Bao Biological Engineering Co., Ltd.). Protein concentrations were measured using a standard Bradford protein assay method. Western blot analysis was performed according to a recently published protocol (22). In brief, $20 \mu \mathrm{g}$ proteins were mixed with equal volume of $2 \mathrm{X}$ loading buffer (Bao Biological Engineering Co., Ltd.) and heated at $95^{\circ} \mathrm{C}$ for $5 \mathrm{~min}$. Proteins were separated with $12 \%$ sodium dodecyl sulfate-polyacrylamide gel electrophoresis (Bao Biological Engineering Co., $\mathrm{Ltd}$ ), then transferred onto polyvinylidene fluoride membranes (Bao Biological Engineering Co., Ltd). The membranes were
Table I. Rate of apoptosis in each group.

Group

Rate of apoptosis (\%)

Control

$5.164 \pm 1.437$

$10 \mathrm{ng} / \mathrm{ml}$ TGF- $\beta 1$

$26.412 \pm 3.235^{\mathrm{a}}$

$20 \mathrm{ng} / \mathrm{ml}$ TGF- $\beta 1$

$38.857 \pm 4.286^{\mathrm{a}}$

Data are presented as the mean \pm standard deviation. ${ }^{\mathrm{a}} \mathrm{P}<0.05 \mathrm{vs}$. control. TGF- $\beta 1$, transforming growth factor- $\beta 1$.

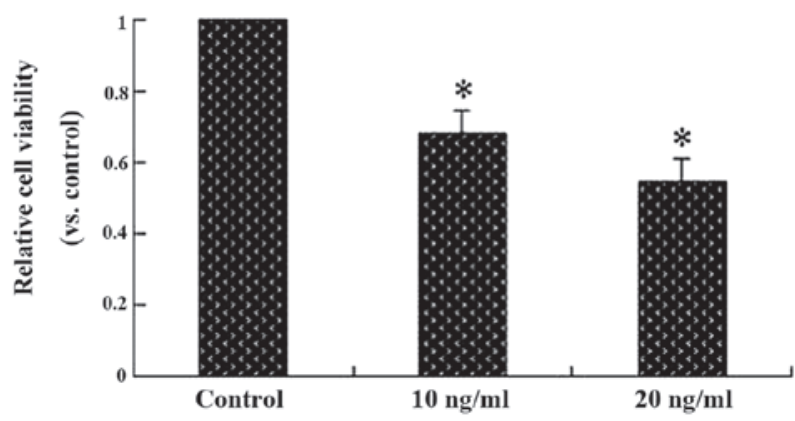

Figure 1. Cell viability of bone marrow-derived mesenchymal stem cells following exposure to 0,10 and $20 \mathrm{ng} / \mathrm{ml}$ transforming growth factor- $\beta 1$ for 24 h. ${ }^{*} \mathrm{P}<0.05$ vs. control.

blocked with 5\% non-fat milk (Bao Biological Engineering Co., Ltd) in Tris-buffered saline with Tween-20 (TBS-T; Beijing Solarbio Science and Technology Co., Ltd., Beijing, China) and incubated with the following primary antibodies: Rabbit polyclonal IgG anti-B-cell lymphoma 2 (Bcl-2; 1:1,000; sc-492; Santa Cruz Biotechnology, Inc., Santa Cruz, CA, USA), rabbit polyclonal IgG anti-Bcl-2-associated X protein (Bax; 1:1,000; sc-493; Santa Cruz Biotechnology, Inc.), rabbit polyclonal IgG anti-Annexin V (1:2,000; ab14196; Abcam, Cambridge, MA, USA) or mouse monoclonal IgG anti- $\beta$ actin (1:2,000; sc-47778; Santa Cruz Biotechnology, Inc.) at $4^{\circ} \mathrm{C}$ overnight. Following washing with TBS-T three times, the membranes were incubated with donkey anti-rabbit IgG-horseradish peroxidase-conjugated secondary antibody (1:10,000; sc-2313; Santa Cruz Biotechnology, Inc.) or donkey anti-mouse IgG-horseradish peroxidase-conjugated secondary antibody (1:10,000; sc-2314; Santa Cruz Biotechnology, Inc.) for $1 \mathrm{~h}$ at room temperature. The immunoreactive bands were visualized with an Enhanced Chemiluminescence Western Blotting Substrate Kit (Thermo Fisher Scientific Inc., Waltham, MA, USA). The mean expression levels of Annexin V, Bax and $\mathrm{Bcl}-2$ in each group were calculated using Image $\mathrm{J}$ software [National Institutes of Health (NIH), Bethesda, MD, USA].

Mitochondrial ROS measurement. Mitochondrial ROS were measured by flow cytometry following staining with MitoSOX ${ }^{\mathrm{TM}}$ Red mitochondrial superoxide indicator (Invitrogen Life Technologies). The BMSCs were plated in 24-well plates, treated with different concentrations of TGF- $\beta 1$ for $24 \mathrm{~h}$ and then detached using $2.5 \%$ trypsin digestion. Following digestion, the cells were suspended in warm PBS and incubated with $5 \mu \mathrm{M}$ MitoSOX reagent for $10 \mathrm{~min}$ at 
Table II. Relative expression levels of Annexin V, Bax and Bcl-2 in each group.

\begin{tabular}{lccr}
\hline Protein & Control & $10 \mathrm{ng} / \mathrm{ml} \mathrm{TGF}-\beta 1$ & $20 \mathrm{ng} / \mathrm{ml} \mathrm{TGF-} \beta 1$ \\
\hline Annexin V (\%) & $58.262 \pm 4.372$ & $74.972 \pm 6.301^{\mathrm{a}}$ & $89.331 \pm 6.996^{\mathrm{a}}$ \\
Bax (\%) & $42.964 \pm 2.438$ & $76.250 \pm 6.152^{\mathrm{a}}$ & $95.952 \pm 5.468^{\mathrm{a}}$ \\
Bcl-2 (\%) & $41.194 \pm 3.875$ & $26.412 \pm 3.235^{\mathrm{a}}$ & $10.513 \pm 3.781^{\mathrm{a}}$ \\
\hline
\end{tabular}

Data are presented as the mean \pm standard deviation. ${ }^{\mathrm{a}} \mathrm{P}<0.05$ vs. control. Bcl-2, B-cell lymphoma-2; Bax, Bcl-2-associated X protein; TGF- $\beta 1$, transforming growth factor- $\beta 1$.
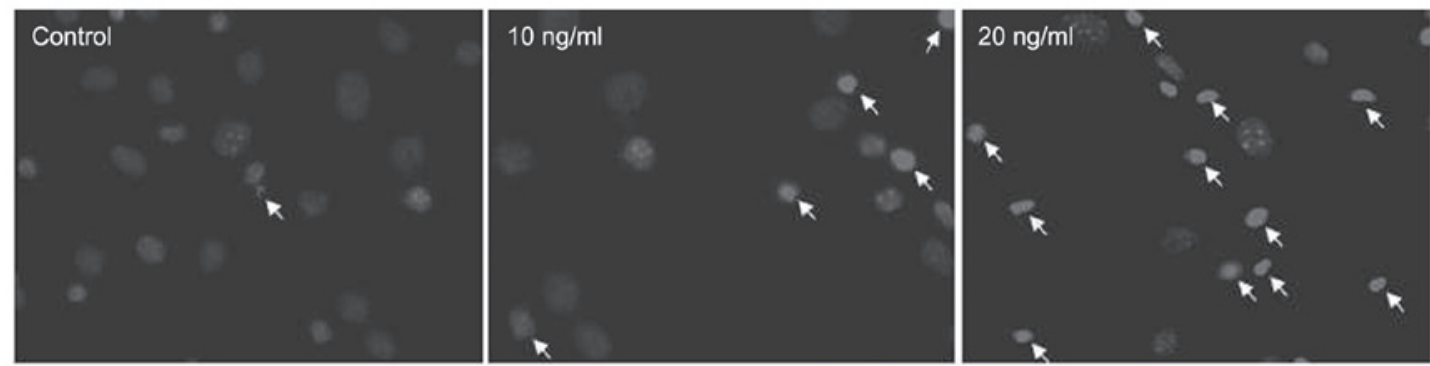

Figure 2. DAPI staining showing apoptosis of bone marrow-derived mesenchymal stem cells following exposure to $0,10 \mathrm{and} 20 \mathrm{ng} / \mathrm{ml}$ transforming growth factor- $\beta 1$ for $24 \mathrm{~h}$. The arrows indicate apoptotic cells with condensed or irregular nuclei (magnification, x200). ${ }^{*} \mathrm{P}<0.05$ vs. control.

$37^{\circ} \mathrm{C}$ in the dark. The cells were then washed thrice with PBS, and the mitochondrial ROS levels were analyzed using flow cytometry (BD Biosciences, San Jose, CA, USA).

Statistical analysis. Statistical analysis was performed with SPSS software (version 16.0; SPSS Inc., Chicago, IL, USA). Data are presented as the mean \pm standard deviation. Univariate comparisons of means were performed using one-way analysis of variance followed by Tukey tests. $\mathrm{P}<0.05$ was considered to indicate a statistically significant difference.

\section{Results}

Effect of TGF- $\beta 1$ on BMSC viability. Compared with the control, treatment with 10 and $20 \mathrm{ng} / \mathrm{ml}$ TGF- $\beta 1$ for $24 \mathrm{~h}$ significantly decreased BMSC viability (Fig. 1).

Effect of TGF- $\beta 1$ on apoptosis of BMSCs. An increased number of cells with a condensed nucleus or a nucleus with irregular edges (DAPI staining) was observed in the TGF- $\beta 1$ (10 and $20 \mathrm{ng} / \mathrm{ml}$ )-treated cells compared with the control cells, which shows that TGF- $\beta 1$ can stimulate BMSC apoptosis (Fig. 2). The mean rate of apoptosis in each group was calculated, and the results are shown in Table I.

Effect of TGF- $\beta 1$ on the expression of apoptotic signals in BMSCs. Annexin $\mathrm{V}$ is an anticoagulant protein that is typically used as an indicator of cell apoptosis. Bcl-2 is an important member of the Bcl-2 family of regulator proteins that inhibits cell apoptosis (23). Bax is an antagonist of Bcl-2 that promotes cell apoptosis (23). Western blotting showed that treatment with 10 and $20 \mathrm{ng} / \mathrm{ml}$ TGF- $\beta 1$ significantly increased the expression of Annexin $\mathrm{V}$ and Bax but decreased the expression of Bcl-2 (Fig. 3). The average

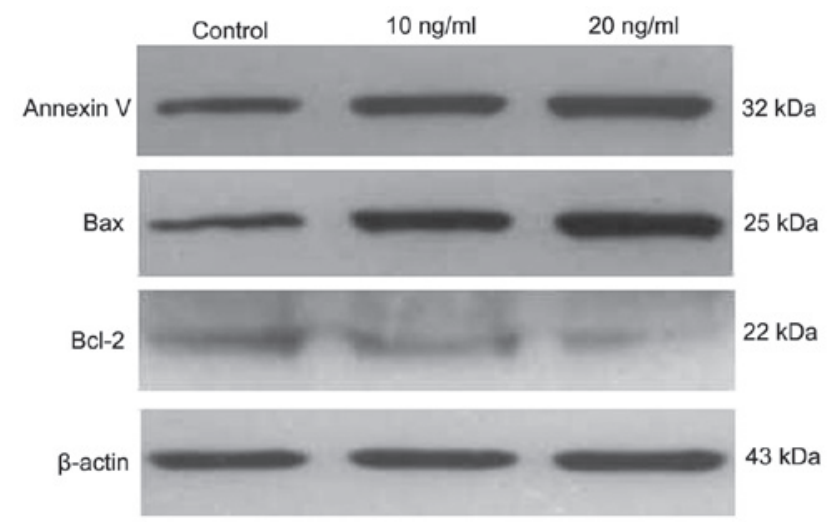

Figure 3. Western blotting showing the expression of Annexin V, Bax and Bcl-2 in bone marrow-derived mesenchymal stem cells following exposure to 0,10 and $20 \mathrm{ng} / \mathrm{ml}$ transforming growth factor- $\beta 1$ for $24 \mathrm{~h}$. Bcl-2, B-cell lymphoma-2; Bax, Bcl-2-associated X protein.
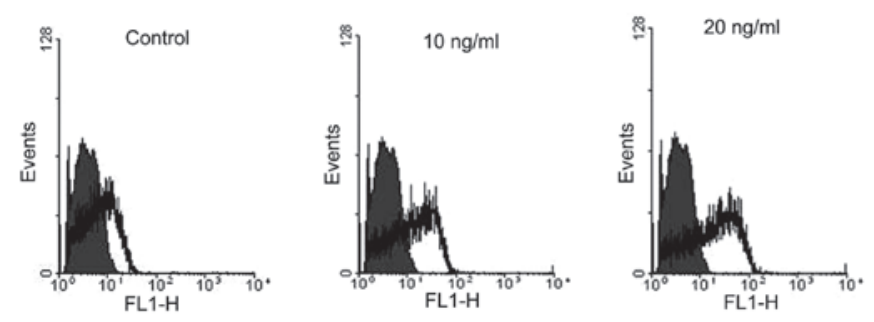

Figure 4. Flow cytometry showing the effect of transforming growth factor- $\beta 1$ on mitochondrial reactive oxygen species in bone marrow-derived mesenchymal stem cells.

expression levels of Annexin V, Bax and Bcl-2 in each group were calculated using Image $\mathbf{J}$ software $(\mathrm{NIH})$ and are listed in Table II. 
Effect of TGF- $\beta 1$ on mitochondrial ROS generation in BMSCs. Mitochondrial ROS are strong inducers of cell apoptosis (24). It has been indicated that TGF- $\beta 1$ can induce mitochondrial ROS production in cell lineages other than BMSCs $(19,25)$. Flow cytometric data showed that treatment with TGF- $\beta 1$ (10 and $20 \mathrm{ng} / \mathrm{ml}$ ) also markedly increased mitochondrial ROS levels in BMSCs (Fig. 4).

\section{Discussion}

BMSCs are the most promising seed cells in stem cell-based transplantation and have been widely used in the clinical treatment of certain diseases, such as neurodegeneration and myocardial infarction (26,27). Generally, BMSCs must be induced in vitro for directional differentiation prior to transplantation. TGF- $\beta 1$ is one of the most commonly used reagents to induce the directional differentiation of BMSCs into cardiomyocyte-like cells (6-8). In the present study, it was found that the viability of the BMSCs was markedly decreased and the apoptosis rates of the BMSCs were increased following exposure to 10 and $20 \mathrm{ng} / \mathrm{ml}$ TGF- $\beta 1$ for $24 \mathrm{~h}$. Furthermore, the mitochondrial ROS levels were notably increased in the TGF- $\beta 1$-treated BMSCs. These results suggest that TGF- $\beta 1$ can induce BMSC apoptosis, with a mechanism that may involve mitochondrial ROS production.

The TGF- $\beta$ proteins comprise a large family of cell regulatory proteins that plays crucial roles in a series of physiological processes, including cell proliferation, differentiation, apoptosis and autophagy, in numerous cell types (9-11). TGF- $\beta$ has three main isoforms: TGF- $\beta 1$, TGF- $\beta 2$ and TGF- $\beta 3$ (28). TGF- $\beta 1$ was the first-identified isoform in the TGF- $\beta$ family, and is the most important isoform in the regulation of cell growth and differentiation (29). A number of studies have used TGF- $\beta 1$ to induce the cardiomyogenic differentiation of BMSCs and have successfully acquired cardiomyocyte-like cells using this method (6-8); however, several lines of evidence suggest that TGF- $\beta 1$ acts to trigger apoptosis of numerous cell types (15-17). In the present study, it was found that TGF- $\beta 1$ inhibited the proliferation and promoted the apoptosis of BMSCs.

Bcl-2 and Bax are two important members of the Bcl-2 family, and their ratio (Bax:Bcl-2) determines the level of cell apoptosis $(23,24)$. In the present study it was found that treatment with TGF- $\beta 1$ (10 and $20 \mathrm{ng} / \mathrm{ml})$ significantly upregulated Bax but downregulated Bcl-2 protein expression in BMSCs. Annexin $\mathrm{V}$ is another apoptotic promoter that preferentially binds phosphatidylserine and promotes cell apoptosis (30). The present results demonstrated that Annexin V was markedly upregulated in BMSCs following exposure to 10 and $20 \mathrm{ng} / \mathrm{ml}$ TGF- $\beta 1$ for $24 \mathrm{~h}$.

Mitochondrial ROS can induce apoptosis via regulation of the balance between Bcl-2 and Bax (24). It has also been demonstrated that mitochondrial ROS mediate the mitochondrial-dependent cell apoptosis induced by TGF- $\beta$ in certain non-BMSC lineages, such as fetal hepatocytes (31). Our previous study demonstrated that TGF- $\beta 1$ induced mitochondrial ROS generation in BMSCs (20). Consistent with these previous data, the results in the present study also demonstrated that TGF- $\beta 1$, at doses of 10 and $20 \mathrm{ng} / \mathrm{ml}$, promoted mitochondrial ROS production in BMSCs. The
TGF- $\beta 1$-mediated mitochondrial ROS production may be responsible for its actions on BMSC apoptosis.

In conclusion, the present study has demonstrated that TGF- $\beta 1$ can promote the apoptosis of BMSCs. The effect of TGF- $\beta 1$ on BMSCs may involve mitochondrial ROS generation.

\section{Acknowledgements}

This study was supported by a grant (no. 31401246) from the National Natural Science Foundation of China.

\section{References}

1. Zhang F, Wang C, Jing S, et al: Lectin-like oxidized LDL receptor-1 expresses in mouse bone marrow-derived mesenchymal stem cells and stimulates their proliferation. Exp Cell Res 319: 1054-1059, 2013.

2. Chen Y, Teng X, Chen W, et al: Timing of transplantation of autologous bone marrow derived mesenchymal stem cells for treating myocardial infarction. Sci China Life Sci 57: 195-200, 2014.

3. Williams AR, Trachtenberg B, Velazquez DL, et al: Intramyocardial stem cell injection in patients with ischemic cardiomyopathy: Functional recovery and reverse remodeling. Circ Res 108: 792-796, 2011.

4. Fan CQ, Leu S, Sheu JJ, et al: Prompt bone marrow-derived mesenchymal stem cell therapy enables early porcine heart function recovery from myocardial infarction. Int Heart $\mathrm{J} 55$ : 362-371, 2014.

5. Tong J, Ding J, Shen X, et al: Mesenchymal stem cell transplantation enhancement in myocardial infarction rat model under ultrasound combined with nitric oxide microbubbles. PLoS One 8: e80186, 2013.

6. Bhang SH, Gwak SJ, Lee TJ, et al: Cyclic mechanical strain promotes transforming-growth-factor-beta-1-mediated cardiomyogenic marker expression in bone-marrow-derived mesenchymal stem cells in vitro. Biotechnol Appl Biochem 55: 191-197, 2010.

7. Mohanty S, Bose S, Jain KG, et al: TGF $\beta 1$ contributes to cardiomyogenic-like differentiation of human bone marrow mesenchymal stem cells. Int J Cardiol 163: 93-99, 2013.

8. Rouhi L, Kajbafzadeh AM, Modaresi M, et al: Autologous serum enhances cardiomyocyte differentiation of rat bone marrow mesenchymal stem cells in the presence of transforming growth factor- $\beta 1$ (TGF- $\beta 1$ ). In Vitro Cell Dev Biol Anim 49: 287-294, 2013.

9. Al-Azayzih A, Gao F, Goc A and Somanath PR: TGF $\beta 1$ induces apoptosis in invasive prostate cancer and bladder cancer cells via Akt-independent, p38 MAPK and JNK/SAPK-mediated activation of caspases. Biochem Biophys Res Commun 427: 165-170, 2012.

10. Li YC, Ding XS, Li HM, et al: Role of G protein-coupled estrogen receptor 1 in modulating transforming growth factor- $\beta$ stimulated mesangial cell extracellar matrix synthesis and migration. Mol Cell Endocrinal 391: 50-59, 2014.

11. Gajewska M, Gajkowska B and Motyl T: Apoptosis and autophagy induced by TGF- $\beta 1$ in bovine mammary epithelial BME-UV1 cells. J Physiol Pharmacol (56 Suppl 3): 143-157, 2005.

12. Huang SS and Huang JS: TGF-beta control of cell proliferation. J Cell Biochem 96: 447-462, 2005.

13. Khan R, Agrotis A and Bobik A: Understanding the role transforming growth factor-beta-1 in intimal thickening after vascular injury. Cardiovasc Res 74: 223-234, 2007.

14. Gonzalez CR, Calandra RS and Gonzalez-Calvar SI: Testicular expression of the TGF- $\beta 1$ system and the control of Leydig cell proliferation. Adv Biosci Biotech 4: 1-7, 2013.

15. Lafon C, Mathieu C, Guerrin M, et al: Transforming growth factor beta 1-induced apoptosis in human ovarian carcinoma cells: Protection by the antioxidant $\mathrm{N}$-acetylcysteine and bcl-2. Cell Growth Differ 7: 1095-1104, 1996.

16. Cencetti F, Bernacchioni C, Tonelli F, et al: TGF $\beta 1$ evokes myoblast apoptotic response via a novel signaling pathway involving S1P4 transactivation upstream of Rho-kinase-2 activation. FASEB J 27: 4532-4546, 2013. 
17. Li X, McFarland DC and Velleman SG: Transforming growth factor-beta 1-induced satellite cell apoptosis in chickens is associated with beta 1 integrin-mediated focal adhesion kinase activation. Poult Sci 88: 1725-1734, 2009.

18. Shimada K, Crother TR, Karlin J, et al: Oxidized mitochondrial DNA activates the NLRP3 inflammasome during apoptosis. Immunity 36: 401-414, 2012.

19. Yoon YS, Lee JH, Hwang SC, et al: TGF beta 1 induces prolonged mitochondrial ROS generation through decreased complex IV activity with senescent arrest in MvLu cells. Oncogene 24: 1895-1903, 2005.

20. Wu J, Niu J, Li X, et al: TGF- $\beta 1$ induces senescence of bone marrow mesenchymal stem cells via increase of mitochondrial ROS production. BMC Dev Biol 14: 21, 2014.

21. Zhang F, Wang C, Wang H, et al: Ox-LDL promotes migration and adhesion of bone marrow-derived mesenchymal stem cells via regulation of MCP-1 expression. Mediators Inflamm 2013: 691023, 2013.

22. Zhang F, Jing S, Ren T and Lin J: MicroRNA-10b promotes the migration of mouse bone marrow-derived mesenchymal stem cells and downregulates the expression of E-cadherin. Mol Med Rep 8: 1084-1088, 2013.

23. Misao J, Hayakawa Y, Ohno M, et al: Expression of bcl-2 protein, an inhibitor of apoptosis and Bax, an accelerator of apoptosis, in ventricular myocytes of human hearts with myocardial infarction. Circulation 94: 1506-1512, 1996.
24. Fleury C, Mignotte B and Vaysière JL: Mitochondrial reactive oxygen species in cell death signaling. Biochimie 84: 131-141, 2002.

25. Abe Y, Sakairi T, Beeson C and Kopp JB: TGF- $\beta 1$ stimulates mitochondrial oxidative phosphorylation and generation of reactive oxygen species in cultured mouse podocytes, mediated in part by the mTOR pathway. Am J Physiol Renal Physiol 305: F1477-F1490, 2013.

26. Wen Z, Zheng S, Zhou C, et al: Repair mechanisms of bone marrow mesenchymal stem cells in myocardial infarction. J Cell Mol Med 15: 1032-1043, 2011.

27. Chen Y, Teng FY and Tang BL: Coaxing bone marrow stromal mesenchymal stem cells towards neuronal differentiation: Progress and uncertainties. Cell Mol Life Sci 63: 1649-1657, 2006.

28. Ruiz-Ortega M,Rodriguez-Vita J,Sanchez-Lopez E, et al:TGF-beta signaling in vascular fibrosis. Cardiovasc Res 74: 196-206, 2007.

29. Xiangming C, Natsugoe S, Takao S, et al: Preserved Smad4 expression in the transforming growth factor beta signaling pathway is a favorable prognostic factor in patients with advanced gastric cancer. Clin Cancer Res 7: 277-282, 2001.

30. Liu T, Zhu W, Yang X, Chen L, Yang R, Hua Z and Li G: Detection of apoptosis based on the interaction between annexin $\mathrm{V}$ and phosphatidylserine. Anal Chem 81: 2410-2413, 2009.

31. Herrera B, Alvarez AM, Sánchez A, et al: Reactive oxygen species (ROS) mediates the mitochondrial-dependent apoptosis induced by transforming growth factor $\beta$ in fetal hepatocytes. FASEB J 15: 741-751, 2001 